\title{
Análise descritiva de cultivares de mamoneira em dois anos de cultivo no recôncavo baiano
}

\author{
Orlando Melo Sampaio Filho ${ }^{1}$ \\ Simone Alves Silva ${ }^{2}$ \\ Henrique Fortes Bahia ${ }^{3}$ \\ Mariana Souza da Silva ${ }^{4}$ \\ Diego dos Santos Carvalho ${ }^{5}$
}

\begin{abstract}
RESUMO: Esta pesquisa teve por objetivo estudar a interação entre quatro genótipos de mamoneira em dois anos de estudo nas condições edafoclimáticas do recôncavo baiano. Os ensaios foram realizados entre os meses de abril de 2006 e fevereiro de 2007, e entre os meses de maio de 2007 e fevereiro de 2008 em área experimental da Universidade Federal do Recôncavo da Bahia, em Cruz das Almas. Foi observado que a cultivar SIPEAL 28 obteve os melhores rendimentos para os dois anos em estudo, demonstrando a possibilidade de utilização deste material para cultivo em baixas altitudes.
\end{abstract}

Palavras-chave: Ricinus communis L.; estabilidade fenotípica; análise conjunta.

\section{INTRODUÇÃO}

A mamona (Ricinus communis L.) é um arbusto de cujo fruto se extrai um óleo de excelentes propriedades, de largo uso como insumo industrial.

Após a Lei № 11097 (jan./2005) houve a inclusão definitiva do biodiesel na matriz energética brasileira. O governo brasileiro implantou o Programa Nacional de Produção e Uso de Biodiesel. Biodiesel é acima de tudo um combustível biodegradável, renovável que pode ser fabricado por reações químicas entre óleos vegetais e animais e alcoóis de baixo peso molecular (TORRES, 2006).

Em todos os países produtores de mamona, esta cultura tem grande importância social por empregar mão-de-obra de trabalhadores rurais, principalmente para o plantio, controle de plantas daninhas e colheita. Em média, emprega-se aproximadamente um trabalhador rural para cada quatro ha de plantio de mamona (EMBRAPA ALGODÃO, 2008).

Segundo Severino et al. (2006), no contexto nacional a Região Nordeste é a principal produtora de mamona, sendo responsável por mais de $90 \%$ da produção Nacional. Entretanto, essa cultura pode ser cultivada em várias regiões do País, encontrando-se plantios comerciais nas Regiões Sul, Sudeste e Centro-Oeste.

1 Eng. Agrônomo, mestre em Ciências Agrárias do Centro de Ciências Agrárias, Ambientais e Biológicas,

Universidade Federal do Recôncavo da Bahia, Campus Universitário s/n, Cruz das Almas, BA, CEP 44380-000.

E-mail: < nandaoagrufba@hotmail.com>.

2 Professor Dr. Adjunto do Centro de Ciências Agrárias, Ambientais e Biológicas, Universidade Federal do Recôncavo da Bahia, Campus Universitário s/n, Cruz das Almas, BA, CEP 44380-000. E-mail: <sas@ufrb.edu.br>

3 Eng. Agrônomo, Doutorando em Energia e Ambiente - CIEnAm, LabLaser - Instituto de Química da Universidade Federal da Bahia Biológicas, Universidade Federal do Recôncavo da Bahia, Rua Barão de Geremoabo, Sala 218, CEP: 40.170-290. Campus de Ondina, Salvador, Bahia, Brasil. E-mail: <bahiahf@yahoo.com.br>.

4 Graduando em Agronomia do CCAAB, Universidade Federal do Recôncavo da Bahia, Cruz das Almas, BA, CEP 44380-000. E-mail: <maryengagr@hotmail.com>.

5 Eng. Agrônomo, mestrando em Ciências Agrárias do Centro de Ciências Agrárias, Ambientais e Biológicas, Universidade Federal do Recôncavo da Bahia, Campus Universitário s/n, Cruz das Almas, BA, CEP 44380-000. E-mail: <diegoagrufba@yahoo.com.br>. 
O Recôncavo Baiano pode se constituir em importante alternativa para ampliação da área cultivada com mamona, devido alguns aspectos importantes. Seu período chuvoso coincide com o da região Nordeste do estado e difere daquele das principais regiões produtoras, portanto, a região do Recôncavo poderá contribuir para o abastecimento do mercado no período de entressafra. Sua proximidade das usinas produtoras de biodiesel localizada em Simões Filho reduzirá o custo do frete, tornando a matéria prima mais competitiva, Silva (2008).

Segundo Cartaxo et al. (2004), mais de quinhentos municípios estão situados no ótimo ecológico para a produção de mamona, conferindo ao Brasil posição de destaque frente a países produtores tradicionais como a Índia e a China. O Brasil pode fornecer a matéria prima necessária ao incremento do programa Biodiesel utilizando melhores tecnologias agrícolas como fertilizante, sementes geneticamente melhoradas e preparo do solo (SANTOS, et al.2001).

Os fenômenos rítmicos, visíveis nas comunidades vegetais, estão relacionados com as mudanças climáticas estacionais. Para se compreender as atividades vitais simultâneas e sucessivas das plantas, as observações isoladas não são suficientes; é necessária uma coleta de dados continua e sistematizada.

Neste sentido, o estudo da interação entre genótipos e ambientes GxE representa aspecto relevante no contexto do melhoramento. Assim sendo, Duarte e Vencovsky (1999) afirmam que o entendimento deste fenômeno torna-se imprescindível aos programas de melhoramento que procuram minimizar a inconsistência das características relacionadas à produtividade frente à variação ambiental, para recomendações mais acertadas.

Esta pesquisa teve por objetivo estudar a interação entre quatro genótipos de mamoneira em dois anos de estudo nas condições edafoclimáticas do Recôncavo baiano, observando a estabilidade fenotípica, com o auxílio da análise conjunta, com a finalidade de identificar genótipos que reúnam características de alta produtividade permitindo assim recomendações regionalizadas.

\section{MATERIAL E MÉTODOS}

O trabalho foi realizado no Centro de Ciências Agrárias, Ambientais e Biológicas (CCAAB) da Universidade Federal do Recôncavo da Bahia, em Cruz das Almas. Segundo Nacif et al. (2008), o município localiza-se na microrregião geográfica Santo Antônio de Jesus, região econômica Recôncavo Sul. Situada no planalto pré litorâneo, Cruz das Almas apresenta clima tropical quente e úmido $(\mathrm{Am})$, segundo a classificação de Köeppen e altitude de $220 \mathrm{~m}$ acima do nível do mar. Com pluviosidade média anual de $1.170 \mathrm{~mm}$, com variações entre 900 e $1.300 \mathrm{~mm}$, sendo os meses de março a agosto os mais chuvosos e de setembro a fevereiro os mais secos. A temperatura média anual é de $24,1^{\circ} \mathrm{C}$.

Os ensaios foram realizados em dois anos agrícolas distintos e consecutivos: entre os meses de abril de 2006 e fevereiro de 2007, e entre os meses de maio de 2007 e fevereiro de 2008 em área experimental.

O material vegetal utilizado para o plantio foi composto por sementes provenientes de quatro cultivares, EBDA MPA 17, Sipeal 28, BRS 188 Paraguaçu, BRS 149 Nordestina, desenvolvidas pela Empresa Baiana de Desenvolvimento Agrícola (EBDA) e EMBRAPA ALGODÃO, sendo obtidas junto ao Banco Ativo de Germoplasma de Mamona da EBDA, estação experimental de Iraquara (BA).

Para a correção do solo foram seguidas as recomendações da análise de fertilidade química, sendo aplicados 1.000 kgha-1 de calcário dolomítico, 60 kg.ha-1 de N (30 kg.ha-1 30 DAE e 30 kg.ha-1 60 DAE), 60 kg.ha-1 de P2O5 e 40 kg.ha-1 de K2O. O controle de ervas daninhas foi realizado mensalmente com capina manual e não foram utilizados 
inseticidas nem fungicidas para combater a lagarta-rosca (Agrotis ipsilon) e o mofo cinzento (A. ricini) respectivamente.

A semeadura foi realizada em regime de sequeiro e o delineamento utilizado foi o de blocos casualizados, com cinco repetições e quatro tratamentos, constituídos pelas cultivares BRS 149 Nordestina, BRS 188 Paraguaçu, EBDA MPA-17 e Sipeal 28. Cada parcela teve as dimensões $12,0 \mathrm{~m} \times 15,0 \mathrm{~m}$, com as linhas laterais constituindo as bordaduras, e a área útil abrangendo as dimensões de 9,0m x 10,0m.

O espaçamento entre fileiras foi de $3,0 \mathrm{~m}$ e entre covas de $1,0 \mathrm{~m}$, resultando em cinco fileiras com 12 covas e 30 covas na área útil do experimento. Foram semeadas três sementes por cova e o desbaste foi realizado aos 10 dias após a emergência, deixando uma planta por cova.

Foram avaliados em cada ano agrícola vinte e três variáveis com o intuito de obter o máximo de informações possíveis a respeito do desempenho da cultura. Os caracteres florescimento do racemo primário (FLO), altura de caule ( $A C)$, comprimento médio de internódios do caule (CMIC), número de internódios do caule (NIC), diâmetro de caule (DC), estatura de planta (EP), comprimento efetivo (útil) de racemo (CER) e rendimento (REND) foram avaliados de acordo com descritores utilizados pela Embrapa Algodão, descritos por Freire et al. (2001).

Para avaliar número de racemos colhidos por planta (NRC), número de racemos emitidos por planta (NREP) e o número de racemos abortados por planta (NRA) foram realizadas contagens periódicas durante todo ciclo da cultura. Para estas aferições, foi considerado racemo abortado aquele que não apresentou frutos ou encontrava-se deformado ou mal-formado com número de frutos inferior a três.

Visando estudar o potencial de enchimento do racemo, foram aferidos comprimento de racemo (CR) e comprimento de racemo sem enchimento (CRSE). Estes caracteres, acrescido do comprimento efetivo do racemo (CER), peso de racemo (PR), peso de frutos por racemo (PFR), peso de sementes por racemo (PSR), número de frutos por racemo (NFR) e número de sementes por racemo (NSR) foram realizados nos três primeiros racemos de cada planta e em 10 plantas ao acaso, utilizando régua e balança digital de precisão.

O estande final (EST) foi determinado contando-se o número de plantas vivas aptas para colheita. Foram realizadas colheitas periódicas a fim de se evitar perdas com deiscência de algumas cultivares, entretanto, a colheita final foi efetuada no mesmo período para todas as cultivares. Os racemos colhidos tiveram os frutos retirados e pesados para determinação do peso de frutos por parcela (PFP).

O peso de frutos por planta (PFPL) foi determinado pela pesagem dos frutos em cada planta. Após secagem ao sol em terreiro, as sementes que não foram removidas dos frutos por deiscência, foram retiradas através de batidas em sacos de alinhagem e as que ainda apresentavam casca aderida, extraídas com alicate de poda manualmente. As sementes foram pesadas para determinação do peso de sementes por parcela (PSP) e a partir deste o REND foi mensurado em função do número de covas da área útil e tamanho da área útil. O peso de sementes por planta (PSPL) foi determinado pela pesagem das sementes de cada planta.

Para a análise de correlação de Pearson foram avaliados todos os caracteres citados acima e eliminados os que apresentaram similaridades através da alta correlação, positiva e significativa, sendo eles: florescimento (FLO), peso de fruto por racemo (PFR), número de fruto por racemo (NFR), peso de fruto por parcela (PFP), peso de fruto por planta (PFPL), peso de semente por parcela (PSP), peso de semente por planta (PSPL).

Os dados foram submetidos à análise de correlação linear de Pearson, análise de variância conjunta e os valores médios foram ordenados segundo o teste de Scott e Knott, 
ao nível de $5 \%$ de probabilidade $(\alpha=0,05)$. As análises foram conduzidas com auxílio dos programas Genes (2001) e SAS System (2001).

\section{RESULTADOS E DISCUSSÃO}

A análise de variância conjunta possibilitou a verificação do efeito significativo de genótipos, ambientes e também da interação genótipos $x$ ambientes, quanto aos caracteres número de racemos emitidos por planta (NREP), número de racemos abortados por planta (NRAP), peso de semente por racemo (PSR) e número de semente por racemo (NSR) o que é evidência de que as classificações dos genótipos não foram coincidentes nos ambientes de avaliação (Tabela 1 e 2).

A base genética da interação genótipos e ambientes origina-se da expressão diferencial dos QTL ao longo dos ambientes e pode ocorrer de três maneiras: um QTL se expressa em um ambiente e não em outro; um QTL se expressa fortemente em determinado ambiente e fracamente em outro; um QTL se expressa de forma diferenciada em diferentes ambientes (ALBRECHT et al., 2007).

Todos os três casos de interação entre QTL e ambientes já foram detectados em trigo (KUMAR et al., 2007; SNAPE et al., 2007).

Portanto, a falta da interação entre genótipos e ambientes, detectada para o caráter número de racemos colhidos (NRC), comprimento efetivo do racemo (CER), comprimento do racemo (CR), comprimento do racemo sem enchimento (CRSE), peso do racemo (PR), altura de caule (AC), estatura de planta (EP), diâmetro de caule (DC), comprimento médio de internódios do caule (CMIC), número de internódios do caule (NIC), estande final (EF) e rendimento (REND) no presente trabalho, é indicativo de que não há, em sua base genética, a ocorrência dos fenômenos genéticos de penetrância e expressividade em seus locos de herança quantitativa.

Tabela 1. Análise de variância conjunta do número de racemos emitidos por planta (NREP), número de racemos colhidos (NRC), número de racemos abortados por planta (NRAP), comprimento efetivo do racemo (CER), comprimento do racemo (CR), comprimento do racemo sem enchimento (CRSE), peso do racemo (PR), peso de semente por racemo (PSR), Cruz das Almas, Recôncavo Baiano, 2006-2007 / 2007-2008.

\begin{tabular}{|c|c|c|c|c|c|c|c|c|c|}
\hline \multirow{2}{*}{$\begin{array}{l}\text { Fontes de } \\
\text { Variação }\end{array}$} & \multirow{2}{*}{$\begin{array}{c}\text { G.L } \\
\text {. }\end{array}$} & \multicolumn{8}{|c|}{ Q.M. } \\
\hline & & NREP & NRC & NRAP & CER & $\mathrm{CR}$ & CRSE & PR & PSR \\
\hline $\begin{array}{c}\text { Bloco } \\
\text { dentro } \\
\text { Época }\end{array}$ & 8 & 12,04 & 8,77 & 2,14 & 2,98 & 1,82 & 1,02 & 82,10 & 54,62 \\
\hline Genótipo & 3 & $104,37 * *$ & $42,36^{* *}$ & $31,67^{* *}$ & $39,74^{*}$ & $67,30 * *$ & $3,66^{\mathrm{ns}}$ & $1189,31^{*}$ & $468,44^{* *}$ \\
\hline Época & 1 & $\begin{array}{c}2408,70^{*} \\
*\end{array}$ & $\underset{*}{1166,40 *}$ & $\underset{*}{221,84 *}$ & $50,60 * *$ & $2,80^{\text {ns }}$ & $\begin{array}{c}109,03 * \\
*\end{array}$ & $\begin{array}{c}1467,61^{*} \\
*\end{array}$ & $534,80^{*}$ \\
\hline $\begin{array}{c}\text { Genótipo } \\
\text { x Época }\end{array}$ & 3 & $56,50^{* *}$ & $14,09^{\mathrm{ns}}$ & $26,35^{* *}$ & $4,82^{\mathrm{ns}}$ & $12,76^{\mathrm{ns}}$ & $3,96^{\mathrm{ns}}$ & $547,68^{\text {ns }}$ & $252,90^{*}$ \\
\hline Resíduo & 24 & 9,80 & 8,18 & 1,70 & 8,95 & 9,87 & 1,95 & 269,10 & 86,90 \\
\hline $\operatorname{CV}(\%)$ & & 22,69 & 27,17 & 39,83 & 18,42 & 13,42 & 18,82 & 17,75 & 18,16 \\
\hline Média & & 13,79 & 10,52 & 3,27 & 16,25 & 23,41 & 7,42 & 92,41 & 51,34 \\
\hline
\end{tabular}

* Significativo ao nível de $5 \%$ de probabilidade pelo teste $\mathrm{F} ;{ }^{* *}$ Significativo ao nível de $1 \%$ de probabilidade pelo teste $\mathrm{F}$. 
Na Tabela 3 encontram-se as médias e sua comparação pelo teste de Scott-Knott dos caracteres em cada genótipo nos dois anos de cultivo. Como estudado por Bahia (2008), houve formação de pelo menos dois grupos em quase todos os caracteres avaliados no primeiro ano. Nesta análise verifica-se no segundo ano apenas sete caracteres obtiveram diferença significativa sendo eles o CER, CR, PR, PSR, AC, EP, NIC, onde a maioria formaram dois grupos e apenas o NIC formou três grupos.

Tabela 2. Análise de variância conjunta do número de semente por racemo (NSR), altura de caule (AC), estatura de planta (EP), diâmetro de caule (DC), comprimento médio de internódios do caule (CMIC), número de internódios do caule (NIC), estande final (EF) e rendimento (REND). Cruz das Almas, Recôncavo Baiano, 2006-2007 / 2007-2008.

\begin{tabular}{|c|c|c|c|c|c|c|c|c|c|}
\hline \multirow{2}{*}{$\begin{array}{l}\text { Fontes de } \\
\text { Variação }\end{array}$} & \multirow{2}{*}{$\begin{array}{c}\text { G.L } \\
\cdot\end{array}$} & \multicolumn{8}{|c|}{ Q.M. } \\
\hline & & NSR & $\mathrm{AC}$ & EP & DC & CMIC & NIC & $\mathrm{EF}$ & REND \\
\hline $\begin{array}{c}\text { Bloco } \\
\text { dentro } \\
\text { Época }\end{array}$ & 8 & 32,132 & 288,58 & 431,95 & 41,01 & 0,19 & 2,19 & 19,51 & 35292,21 \\
\hline Genótipo & 3 & $703,40^{*}$ & $234,16^{\mathrm{ns}}$ & $\begin{array}{c}3059,02^{*} \\
*\end{array}$ & $60,34^{\mathrm{ns}}$ & $0,94 *$ & $9,77^{* *}$ & $37,27^{\text {ns }}$ & $180879,50^{\mathrm{ns}}$ \\
\hline Época & 1 & $1080,56^{* *}$ & $57,86^{\mathrm{ns}}$ & $\begin{array}{c}106048,8 \\
0^{* *}\end{array}$ & $\begin{array}{c}2742,17^{*} \\
*\end{array}$ & $5,45^{* *}$ & $\begin{array}{c}25,44^{*} \\
*\end{array}$ & $\begin{array}{c}940,90^{*} \\
*\end{array}$ & $4459855,60^{\mathrm{ns}}$ \\
\hline $\begin{array}{c}\text { Genótipo } \\
\text { x Época }\end{array}$ & 3 & $475,746^{*}$ & $111,12^{\mathrm{ns}}$ & $360,86^{\mathrm{ns}}$ & $18,24^{\mathrm{ns}}$ & $0,27^{\mathrm{ns}}$ & $0,13^{\text {ns }}$ & $8,43^{\text {ns }}$ & $56899,42^{\mathrm{ns}}$ \\
\hline Resíduo & 24 & 160,25 & 719,28 & 438,77 & 62,07 & 0,20 & 0,66 & 16,41 & 68591,91 \\
\hline CV (\%) & & 15,05 & 9,21 & 12,89 & 18,66 & 11,14 & 5,38 & 17,61 & 32,84 \\
\hline Média & & 84,12 & 59,46 & 162,53 & 42,22 & 4,04 & 15,15 & 23 & 797,59 \\
\hline
\end{tabular}

* Significativo ao nível de $5 \%$ de probabilidade pelo teste F; ** Significativo ao nível de $1 \%$ de probabilidade pelo teste $\mathrm{F}$.

Os efeitos de ambientes foram responsáveis pela maior parte da variação, seguido dos efeitos de genótipos e da interação genótipo x ambiente. Esses resultados concordam com os obtidos por Akande (2007), que estudou a interação genótipo x ambiente para a produtividade de grãos de oito cultivares de feijão-caupi no sudoeste africano, e encontraram maior variação para ambientes.

Ramos et al. (2008), encontrou valores bem abaixo para a característica porte do vegetal, com uma média de $85,81 \mathrm{~cm}$ e um CV de 9,89\%.

O rendimento variou de $282,23 \mathrm{~kg}$ ha-1 á $1347,33 \mathrm{~kg}$ ha- 1 nos dois anos, essa variação é atribuída às diferenças ambientais nas duas situações. Brito et al. (2004), também avaliaram genótipos de mamoneira plantados em baixa altitude e obtiveram produtividades variando de 654 kg ha-1 a 1.210 kg.ha-1, com média de 896,3 kg.ha-1. 
Tabela 3. Médias das características agronômicas de quatro cultivares de mamoneira avaliadas em Cruz das Almas - BA, Recôncavo Baiano, 2006-2007 / 2007-2008.

\begin{tabular}{|c|c|c|c|c|c|c|c|c|}
\hline & & ANO & & & & ANO o & & \\
\hline & Nordestina & Paraguaçu & $\begin{array}{c}\text { EBDA } \\
\text { MPA } 17\end{array}$ & Sipeal & Nordestina & Paraguaçu & $\begin{array}{c}\text { EBDA } \\
\text { MPA } \\
17 \\
\end{array}$ & Sipeal \\
\hline RREP & $23.62 b$ & $28.10 \mathrm{a}$ & $15.20 \mathrm{c}$ & $19.28 \mathrm{c}$ & $6.12 \mathrm{a}$ & $6.86 \mathrm{a}$ & $4.40 \mathrm{a}$ & $6.74 a$ \\
\hline NRC & $16.10 \mathrm{a}$ & $18.80 \mathrm{a}$ & $11.36 \mathrm{~b}$ & $17.44 \mathrm{a}$ & $5.24 \mathrm{a}$ & $5.64 a$ & $3.82 \mathrm{a}$ & $5.80 \mathrm{a}$ \\
\hline RRAP & $7.52 \mathrm{c}$ & $9.30 \mathrm{a}$ & $3.84 \mathrm{~b}$ & $1.84 \mathrm{~d}$ & $0,88 \mathrm{a}$ & $1,24 \mathrm{a}$ & $0,60 \mathrm{a}$ & $0,94 a$ \\
\hline CER & $18,01 \mathrm{a}$ & $14,86 a$ & $18,50 \mathrm{a}$ & $18,12 \mathrm{a}$ & $17,14 a$ & $11,80 \mathrm{~b}$ & $14,73 a$ & $16,82 \mathrm{a}$ \\
\hline CR & $24,14 a$ & $19,40 \mathrm{~b}$ & $25,14 a$ & $23,90 a$ & $25,50 \mathrm{a}$ & $19,85 b$ & $22,62 b$ & $26,74 a$ \\
\hline RSE & $6,13 a$ & $4,54 a$ & $6,64 a$ & $5,78 \mathbf{a}$ & $9,55 \mathbf{a}$ & $8,63 a$ & $8,13 a$ & $9,99 a$ \\
\hline PR & $96,16 \mathrm{a}$ & $92,77 \mathbf{a}$ & $97,50 a$ & $107,44 a$ & $99,30 a$ & $76,64 b$ & $66,63 b$ & $102,84 a$ \\
\hline PSR & $49,52 a$ & $52,37 \mathbf{a}$ & $54,44 a$ & $63,66 a$ & $54,61 \mathrm{a}$ & $43,61 b$ & $35,03 b$ & $57,48 \mathbf{a}$ \\
\hline NSR & $71,94 b$ & $67,58 b$ & $97,04 a$ & $79,14 b$ & $99,20 \mathrm{a}$ & $79,26 a$ & $90,61 a$ & $88,21 \mathrm{a}$ \\
\hline $\mathbf{A C}$ & $58,76 \mathrm{~b}$ & $57,42 b$ & $66,65 a$ & $59,81 b$ & $58,08 \mathrm{a}$ & $55,03 a$ & $58,90 \mathrm{a}$ & $61,00 \mathrm{a}$ \\
\hline EP & $194,58 \mathrm{a}$ & $219,58 \mathrm{a}$ & $208,26 a$ & $233,66 a$ & $103,14 b$ & $109,14 b$ & $92,38 b$ & $139,50 \mathrm{a}$ \\
\hline DC & $52,04 a$ & $49,48 \mathbf{a}$ & $49,86 a$ & $50,63 a$ & $39,12 \mathrm{a}$ & $31,37 a$ & $30,83 a$ & $34,44 a$ \\
\hline MIC & $3,93 b$ & $4,19 b$ & $4,81 \mathrm{a}$ & $4,69 \mathrm{a}$ & $3,48 \mathrm{a}$ & $3,54 a$ & $3,60 \mathrm{a}$ & $4,05 a$ \\
\hline NIC & $15,76 a$ & $14,14 b$ & $14,26 b$ & $13,26 b$ & $17,08 \mathrm{a}$ & $15,90 \mathrm{~b}$ & $16,06 \mathrm{~b}$ & $14,76 \mathrm{c}$ \\
\hline $\mathbf{E F}$ & $14,40 \mathrm{a}$ & $18,60 a$ & $20,20 \mathrm{a}$ & $19,40 \mathrm{a}$ & $26,60 \mathrm{a}$ & $26,40 \mathrm{a}$ & $29,40 \mathrm{a}$ & $29,00 \mathrm{a}$ \\
\hline REND & $968,89 a$ & $1123,33 a$ & $1086,45 a$ & $1347,33 a$ & $516,73 a$ & $419,34 a$ & $282,23 \mathrm{a}$ & $636,42 a$ \\
\hline
\end{tabular}

(1) NREP: número de racemos emitidos por planta; NRC: número de racemos colhidos por planta; NRAP: número de racemos abortados por planta; CER: comprimento efetivo de racemo; CR: comprimento de racemo; CRSE: comprimento de racemo sem enchimento; PR: peso de racemo; PSR: peso de sementes por racemo; NSR: número de sementes por racemo; AC: altura de caule; EP: estatura de planta; DC: diâmetro de caule; CMIC: comprimento médio de internódios do caule; NIC: número de internódios do caule; EST: estande final; REND: rendimento; médias seguidas de letras iguais, na linha, não diferem entre si pelo teste de Scott-Knott, a $5 \%$ de probabilidade.

\section{CONCLUSÕES}

1. As diferenças climáticas entre os dois anos evidenciaram uma expressividade bem distinta para os genótipos dentro de cada ano, mostrando a flexibilidade dos materiais de se adaptarem às flutuações das condições ambientais.

2. O plantio no mês de abril é mais favorável para o desenvolvimento da cultura do que a semeadura realizada na segunda quinzena do mês de maio, pois existe um maior aproveitamento do período chuvoso no Recôncavo Baiano.

3. Foi observado que a cultivar SIPEAL 28 obteve os melhores rendimentos para os dois anos em estudo, demonstrando a possibilidade de utilização deste material para cultivo em baixas altitudes. 


\section{REFERÊNCIAS}

AKANDE, S. R. Genotype by environment interaction for cowpea seed yield and disease reactions in the forest and derived savanna agro-ecologies of south-west Nigeria. AmericanEurasian Journal of Agricultural \& Environmental Science, v. 2, p. 163 -168, 2007.

ALBRECHT J. C.; VIEIRA E. A. et al. Adaptabilidade e estabilidade de genótipos de trigo irrigado no Cerrado do Brasil Central. Pesquisa Agropecuária Brasileira, Brasília, v. 42, n. 12, p. 1727 - 1734, dez. 2007.

BAHIA, H. F. et al. Divergência genética entre cinco cultivares de mamoneira. Pesquisa Agropecuária Brasileira, Brasília, v. 43, n. 3, p.357 - 362, mar. 2008.

BRITO, F. B. et al. Competição de genótipos de mamoneira em baixas altitudes: resultados preliminares. In: CONGRESSO BRASILEIRO DE MAMONA, 1., 2004, Campina Grande. Anais... Campina Grande: Embrapa Algodão, 2004. 1 CD-ROM.

CARTAXO, W. V. et al. O cultivo da mamona no semi-árido brasileiro. Embrapa Algodão. 2004. 20 p. (Circular técnica, 77).

DUARTE, J. B.; VENCOVSKY, R. Interação genótipos x ambientes: uma introdução à análise AMMI. Ribeirão Preto: Sociedade Brasileira de Genética, 1999. 60p. (Série Monografias, 9).

EMBRAPA ALGODÃO. Cadeia Produtiva - Óleo de Mamona e Biodiesel. Disponível em: <http://www.cnpa.embrapa.br/produtos/mamona/cadeia_produtiva_biodiesel.html> . Acesso em: 24 ago. 2008.

KUMAR, N. et al. QTL mapping for yield and yield contributing traits in two mapping populations of bread wheat. Molecular Breeding, v. 19, p. 163 - 177, 2007.

NACIF, P. G. S. et al.. Efeitos da subsolagem em propriedades físico-hídricas de um latossolo amarelo distrocoeso do Estado da Bahia. Magistra, Cruz das Almas - BA, v. 20, n. 2, p. 186 - 192, abr./ jun., 2008.

RAMOS, N. P. et. al. Semeadura do híbrido lyra de mamona (ricinus communis I.) sob plantio direto. Ciência Agrotécnica, Lavras, v. 32, n. 2, p. 481 - 486, mar./abr., 2008.

SANTOS, R. F. et al. Análise Econômica. In: AZEVEDO, D. M. P. de.; LIMA, E. F. (Eds.). 0 agronegócio da mamona no Brasil. EMBRAPA-SPI, 2001. p. 17 - 35.

SILVA, V. Características fisiológicas de cultivares de mamoneira (ricinus communis I.) no recôncavo baiano. Originalmente apresentado como dissertação de mestrado em Fitotecnia. Centro de Ciências Agrárias, Ambientais e Biológicas da Universidade Federal do Recôncavo da Bahia, Cruz das Almas, 2008. 74 f.

SNAPE, J. W. et. al. Dissecting gene x environmental effects on wheat yields via QTL and physiological analysis. Euphytica, v. 154, p. 401 - 408, 2007.

TORRES, Ednildo Andrade et al. Biodiesel: o combustível para o novo século. Bahia Análise \& Dados, Salvador: SEI, v. 16, n. 1, p. 89 - 95, jun. 2006. 